\title{
ELECTROCHEMICAL OXIDATION OF ETHYLENE AT PANI/Pt AND Ag/PANI/Pt MODIFIED ELECTRODES
}

\author{
Lenys Fernández ${ }^{\mathrm{a}, *}$, Edison Omar Martínez ${ }^{\mathrm{b}}$ and Hicher Zambrano ${ }^{\mathrm{c}}$ \\ a'Departamento de Química, Universidad Simón Bolívar, Apartado 89000, Caracas 1080-A, Venezuela

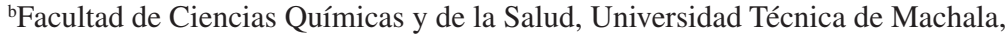 \\ Apartado 070151, Machala, Ecuador \\ 'Facultad de Ingeniería, Universidad de Los Andes, Apartado 5101, Mérida, Venezuela
}

Recebido em 20/12/2015; aceito em 18/04/2016; publicado na web em 08/07/2016

\begin{abstract}
The electrochemical behavior of ethylene on PANI/Pt and Ag/PANI/Pt modified electrodes was investigated in different media. Morphology of the deposits of PANI were observed by SEM analysis, complemented by the EDX techniques to obtain the Ag composition that shows that $\mathrm{Ag}$ is deposited in the polymeric matrix which covered the whole platinum surface. The electrodic system comprising Ag/PANI/ Pt electrode exhibited a more important electrocatalytic response for ethylene oxidation in neutral solutions than the PAN/Pt and Pt electrodes at $20^{\circ} \mathrm{C}$. The results suggest that the oxidation of ethylene on Ag/PANI/Pt electrode is limited by adsorption-controlled reaction while the oxidation at PANI/Pt is mass transport-limited.
\end{abstract}

Keywords: ethylene electrooxidation; polyaniline; electrocatalysis; silver microparticles.

\section{INTRODUCTION}

The use of electrochemical reactions to produce species capable of initiating polymerization processes, has allowed obtaining products that conventionally cannot be obtained, which can be drawn much benefit. It may solve problems, such as improving the energy conversion to electricity, its accumulation and development of new methods for production of substances without danger of contamination, among others. An example of this is anodically oxidize organic compounds such as methanol, ethylene, etc., to convert the chemical energy contained in their bonds directly into electricity, by designing electrocatalysts. At present, there is considerable interest in the use of hydrocarbon oxidation reactions as a source of energy and the use of raw material for obtaining other products of great industrial importance. Traditionally in the sixties, the electrochemical oxidation of ethylene on noble metals was studied at high temperature $\left(80^{\circ} \mathrm{C}\right)$ and $\mathrm{pH} .{ }^{1-3}$ Under these conditions, ethylene can only be anodically oxidized to $\mathrm{CO}_{2}{ }^{4-6}$

$$
\mathrm{C}_{2} \mathrm{H}_{4}+4 \mathrm{H}_{2} \mathrm{O} \rightarrow 2 \mathrm{CO}_{2}+12 \mathrm{H}^{+}+12 \mathrm{e}^{-}
$$

Electrocatalytic applications utilizing conducting polymer should offer a potential increase in operational efficiency, and this has been the subject of a great deal of investigations. Polyaniline (PANI) is particularly interesting among the conducting polymers because of its stability under atmospheric condition and its good conductivity. ${ }^{7-9}$ It has been found that PANI offers a protective matrix for Pt microparticles dispersed into the polymer films. ${ }^{10-14}$ To our best knowledge, there is no formal report about electrochemical oxidation of ethylene at polymer modified electrode. In the present report, we discuss the ethylene preliminary results of electrochemical oxidation behavior on PANI/Pt and on PANI/Pt with dispersed Ag.

\section{EXPERIMENTAL}

\section{Reagents}

Aniline (Aldrich) was used immediately after distilling under reduced pressure. Ethylene (Mathesson, $99.99 \%$ purity) was used directly, $\mathrm{H}_{2} \mathrm{SO}_{4} 95-99 \%, \mathrm{HCl} 37 \%, \mathrm{Na}_{2} \mathrm{SO}_{4} 99 \%, \mathrm{Na}_{2} \mathrm{ClO}_{4}$ reagent grade quality were purchased from Riedel-de Haën. These and all other reagent grade chemicals were used as received.

\section{Apparatus}

Electrochemical measurements were performed in a conventional three-electrode cell. The working electrode was a modified Pt (0.6 $\mathrm{cm}^{2}$ real surface) and a graphite carbon was used as the counter-electrode $\left(1.5 \mathrm{~cm}^{2}\right.$ real surface $)$. All potentials in the paper are reported vs. $\mathrm{Ag} / \mathrm{AgCl}$.

The experiments were carried out using an EG\&G model PAR 273A Potentiostat- Galvanostat, under direct computer control. The morphology and composition of the polymer-catalyst assemblies were determined using a Hitachi S-2500 scanning electron microscope.

\section{RESULTS AND DISCUSSION}

\section{Formation and characterization of the PANI and Ag-PANI films at Pt electrodes}

Preparation and electrochemical response of the modified electrodes polyaniline- modified electrodes were obtained by continuous cycling of the electrode potential and a pulse technique. Film formation was examined in different electrolytes $\left(\mathrm{H}_{2} \mathrm{SO}_{4}, \mathrm{NaClO}_{4}\right.$, $\mathrm{Na}_{2} \mathrm{SO}_{4}$ ). The redox couple response was obtained in the three systems, however, in $0.60 \mathrm{~mol} \mathrm{~L}^{-1} \mathrm{H}_{2} \mathrm{SO}_{4}$ and $0.25 \mathrm{~mol} \mathrm{~L}^{-1} \mathrm{Na}_{2} \mathrm{SO}_{4}$, the behavior was most reproducible, and the results presented there are in this media.

Figure 1 shows the voltammograms of PANI formation by a cyclic voltammetric $(\mathrm{CV})$ technique after ten cycles on a platinum electrode, obtained between -0.600 and $0.800 \mathrm{~V}$ in $0.60 \mathrm{~mol} \mathrm{~L}^{-1} \mathrm{H}_{2} \mathrm{SO}_{4}$, 
$0.25 \mathrm{~mol} \mathrm{~L}^{-1} \mathrm{Na}_{2} \mathrm{SO}_{4}, 0.25 \mathrm{~mol} \mathrm{~L}^{-1}$ aniline at $20{ }^{\circ} \mathrm{C}$. The multiple redox waves indicate the complexity of the electrooxidation of aniline which involves the coupled multiple heterogeneous electron transfer reactions and homogeneous chemical. ${ }^{15-21}$ The literature reports that the PANI films formed at slow scan rates were very different from those produced at fast scans. The difference arises from different reactions in the polymerization pathways ${ }^{22}$ that are important at different time scales. In this work, the PANI films had been synthesized at slow rates $\left(10 \mathrm{mV} \mathrm{s}^{-1}\right)$. Different electrooxidation process of PANI had been proposed ${ }^{22}$ the redox current corresponds to the formation/ removal of the radical cation (polaron) sites in the PANI polymer chain. PANI differs from the majority of organic conducting polymers in that the counterions needed for electroneutrality are protons chemically bonded to the polymer backbone, this might lessen the degree of localization due to an irregular coulomb potential; their electrostatic repulsion causes a Peierls' distortion, and the distortion favors the formation of an energy gap. ${ }^{23}$ Thus, the fully oxidized state loses the conductivity.

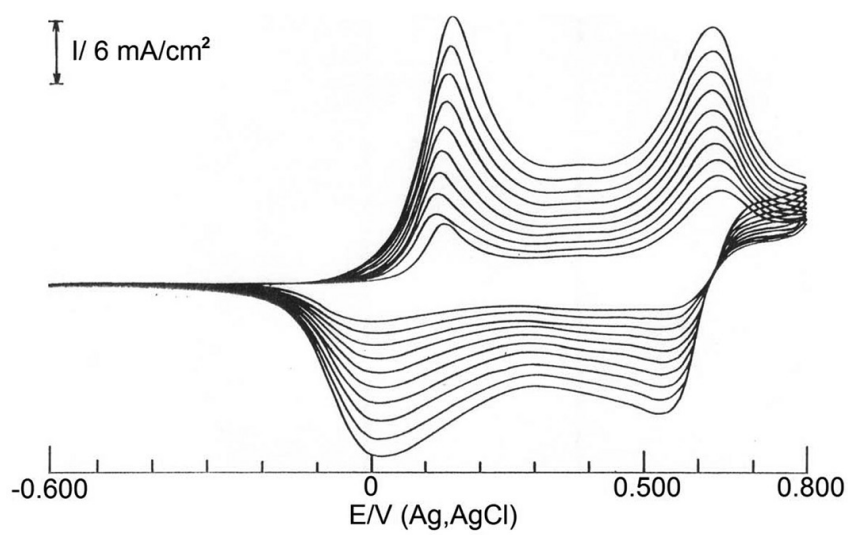

Figure 1. Cyclic voltammograms of electrodeposition of PANI from $0.25 \mathrm{~mol} \mathrm{~L}^{-1}$ aniline in $0.60 \mathrm{~mol} \mathrm{~L}^{-1} \mathrm{H}_{2} \mathrm{SO}_{4}$ and $0.25 \mathrm{~mol} \mathrm{~L}^{-1} \mathrm{Na}_{2} \mathrm{SO}_{4}$, $v=10 \mathrm{mV} \mathrm{s}^{-1}, \mathrm{~T}=20^{\circ} \mathrm{C}$

SEM examined the film formed at a slow scan rate $\left(10 \mathrm{mV} \mathrm{s}^{-1}\right)$. The topography of the film (Figure 2a) shows that the polymer is both amorphous and highly porous, with micro-peaks and micro-valley. In Figure $2 \mathrm{~b}$, the higher magnification micrograph reveals particles of uniform size with a chain microfiber structure. The fiber thickness was about $0.36 \mu \mathrm{m}$, which exhibited some branching. Gaps of approximately 90 $\mu \mathrm{m}$ were observed between branches. Similar microstructures have been previously reported for PAN films prepared in the presence of $\mathrm{H}_{2} \mathrm{SO}_{4}$ or $\mathrm{HCl}$, this morphology is characteristic of the emeraldine state..$^{24,25}$

In Figure 3, the PANI films obtained by a pulse technique in the similar solutions to the $\mathrm{CV}$ case are shown. The potentiostatic synthesis was performed at $0.600 \mathrm{~V}$. Variations of the preparation technique produce morphology changes, which has a flakes structure of low porosity, it is denser, irregular and with large flakes in comparison to that obtained with $\mathrm{CV}$. This characteristic has been associated to a very fast polymer growth. This morphology type is very similar to that present when PANI is synthesized via $\mathrm{CV}$ at scan rates higher than $200 \mathrm{mV} \mathrm{s}^{-1}$. In this work, the PANI/Pt was prepared by $\mathrm{CV}$ at 10 $\mathrm{mV} \mathrm{s}^{-1}$, since ethylene electrooxidation was the most reproducible.

The oxidation charge, $\mathrm{Q}$, of the final voltammetric curve was used as a relative measurement of film thickness and it was compared with that obtained from chronocoulometry. The total charge passing the electrode was measured and ranged from 200 to $400 \mu \mathrm{C}$. The film obtained when $\mathrm{Q}=225 \mu \mathrm{C} \mathrm{cm}^{-2}$ was chosen for the electrode modification. The film thickness was estimated from the film capacitance using the thickness data reported by Wrighton et al. ${ }^{26}$ The film thickness
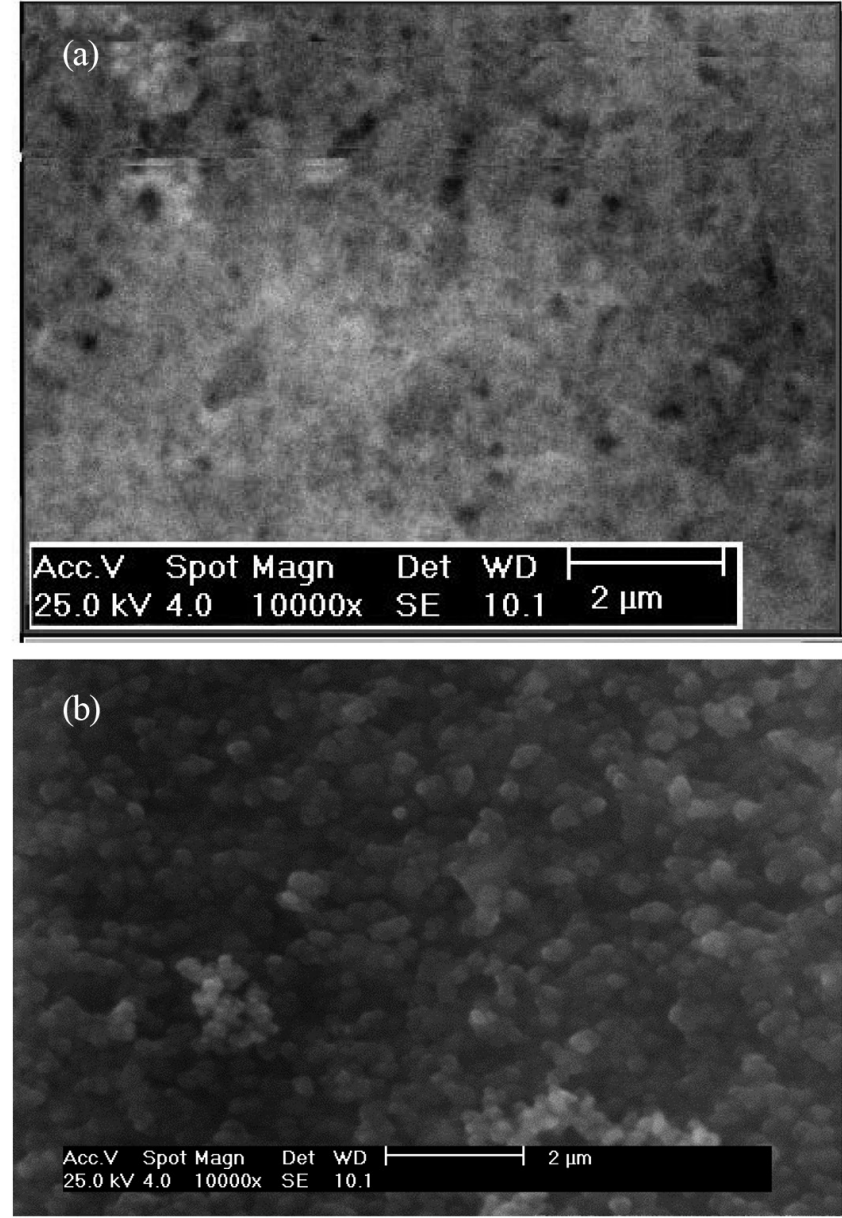

Figure 2. Scanning electron micrographs of PANI film $(2.7 \mu \mathrm{m})$, grown on a platinum electrode by $\mathrm{CV}$, at two different magnifications

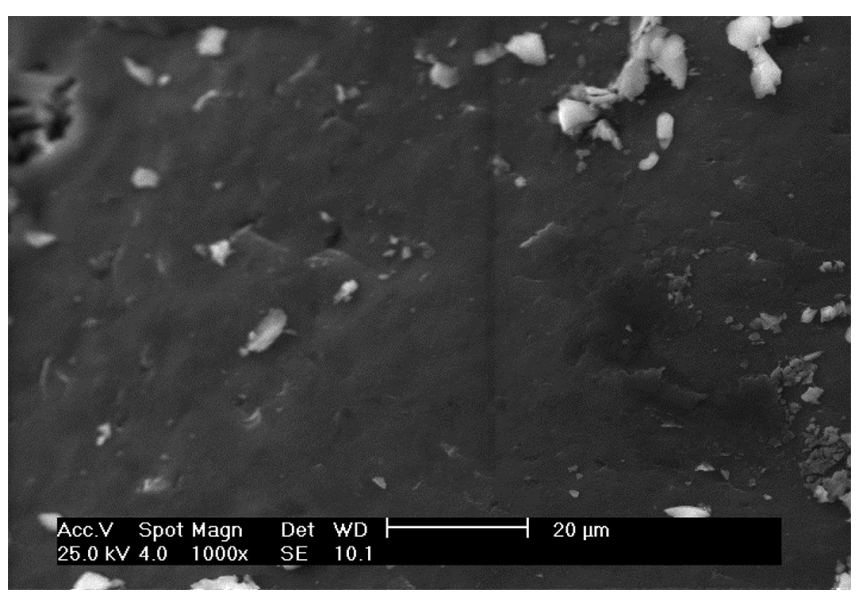

Figure 3. Scanning electron micrographs of PANI film, grown on a platinum electrode under potentiostatic conditions at $0.600 \mathrm{~V}$

for deposition under these conditions was $2.7 \mu \mathrm{m}$.

Electrodeposition of silver on the polymer-coated electrode was carried out at constant potential $(-0.200 \mathrm{~V} v s . \mathrm{Ag} / \mathrm{AgCl})$ from a $1 \mathrm{x}$ $10^{-3} 25 \mathrm{~mol} \mathrm{~L}^{-1} \mathrm{AgNO}_{3}$ solutions. After each transient, the charge for $\mathrm{Ag}$ deposition was $127 \mu \mathrm{C}$.

Scanning electron microscopy reveals a transition in the growth mode and $\mathrm{Ag}$ atoms finely dispersed on the polymer surface as well as embedded into the PANI fibrils (Figure 4a). At higher Ag loading $(127 \mu \mathrm{C})$, silver clusters were irregularly covering the polymer surface (Figure $4 \mathrm{~b}$ ). The EDX shows that Ag grows on the polymer and not 

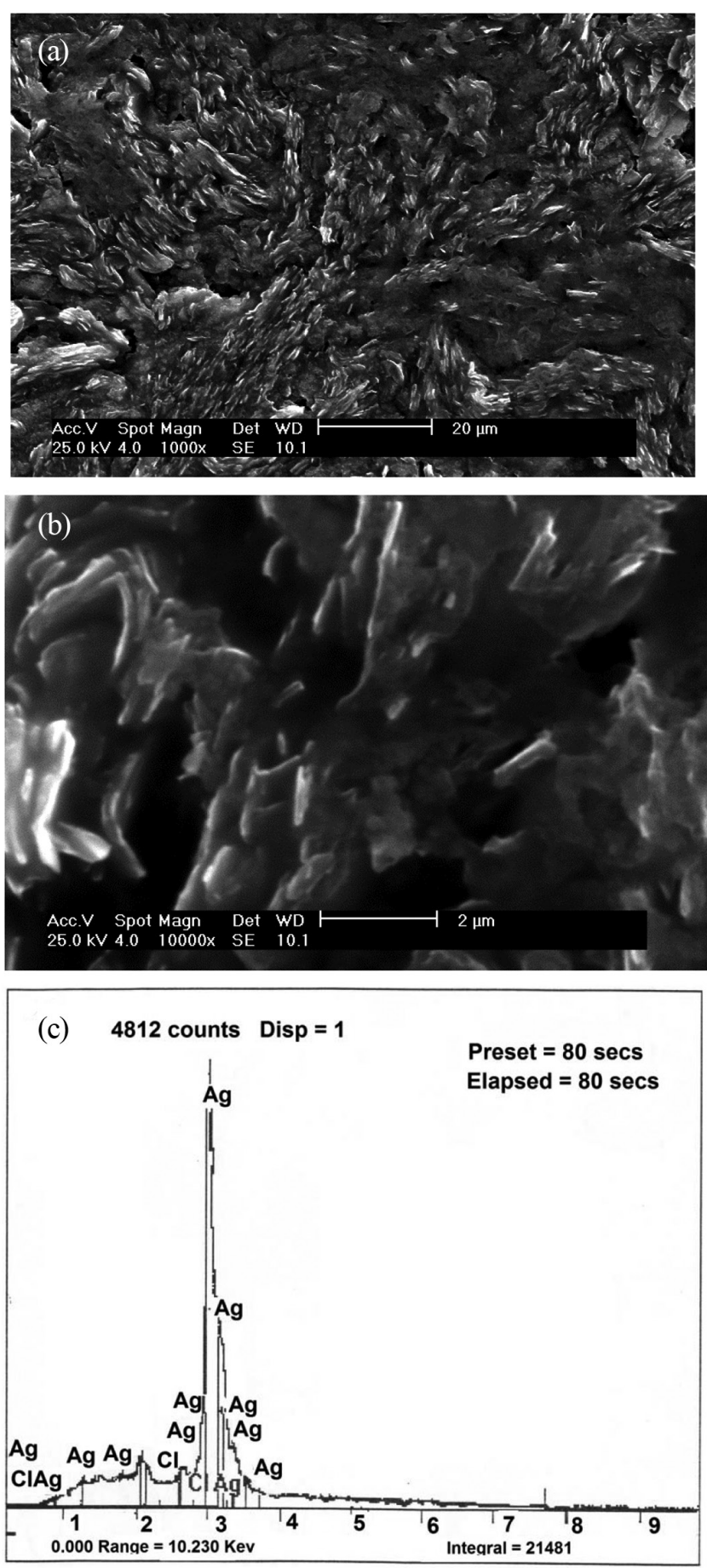

Figure 4. Scanning electron micrographs of silver microparticles in a polyaniline film, at two different magnifications $(a, b)$. The PANI film was prepared by the $C V$ under conditions of Figure 1. EDX spectrum of silver deposited electrochemically on PANI (c)

on the platinum surface (Figure 4c). The PANI/Pt and Ag/PANI/Pt modified electrodes showed a remarkable stability in neutral solutions and no visible polymer degradation was observed after more than $5 \mathrm{~h}$.

Electrochemical response of modified electrodes in the presence of ethylene

The platinum electrode has no ethylene oxidation activity in a neutral medium $\left(0.25 \mathrm{~mol} \mathrm{~L}^{-1} \mathrm{NaClO}_{4}\right)$ at $20^{\circ} \mathrm{C}$, Figure 5 .

In neutral $\mathrm{pH}$ solution, the conductive properties of polyaniline

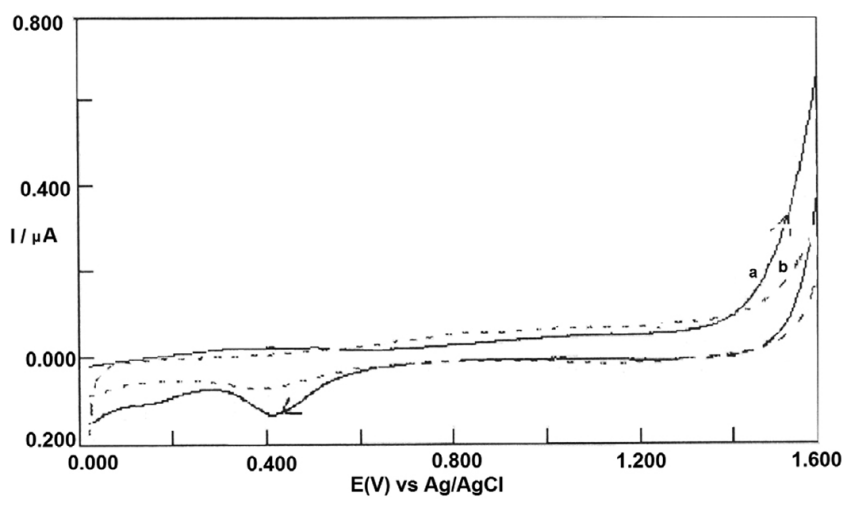

Figure 5. Cyclic voltammetric behavior of ethylene at Pt electrode in 0.25 mol L $\mathrm{Na}_{2} \mathrm{ClO}_{4}, \mathrm{v}=10 \mathrm{mV} \mathrm{s}^{-1}, \mathrm{~T}=20^{\circ} \mathrm{C}$. In saturated solutions of: (a) $\mathrm{Ar}$ and $(b)$ ethylene

can be favored between 0 and $1.0 \mathrm{~V}$, a potential range where the polyaniline is also stable. Figure 6 shows the stable ethylene oxidation voltammetric curves at PANI/Pt (Figure 6b), Ag/PANI/Pt (Figure 6c) and Pt (Figure 6a) modified electrodes in $0.25 \mathrm{~mol} \mathrm{~L}^{-1} \mathrm{NaClO}_{4}$, at $20 \mathrm{mV} \mathrm{s}^{-1}$. In this neutral solution, ethylene oxidation current at PANI/Pt begins to increase at $0.800 \mathrm{~V}$ and one anodic peak is detected, which is significantly different from the onset of ethylene oxidation on the Ag/PANI/ Pt which occurs at $0.650 \mathrm{~V}$. The current in the last case was higher by a factor of two compared to that on the PANI/Pt modified electrode. This could be a consequence of the active sites distribution and its uniformity requiring less positive potentials for ethylene oxidation, taking place on energetically more favored sites. The current density and potential data obtained at PANI/Pt and Ag/ PANI/Pt electrodes modified in different electrolytic medias $\left(\mathrm{Na}_{2} \mathrm{SO}_{4}\right.$ and $\mathrm{NaClO}_{4}$ ) show the responses most favorable for $\mathrm{Ag} / \mathrm{PANI} / \mathrm{Pt}$ electrode in $\mathrm{NaClO}_{4}$. In this case, a catalytic effect in current density $(2.162 \mu \mathrm{A})$ and potential shifted to a less positive value $(0.650 \mathrm{~V})$ in relation to the oxidation of ethylene at PANI/Pt.

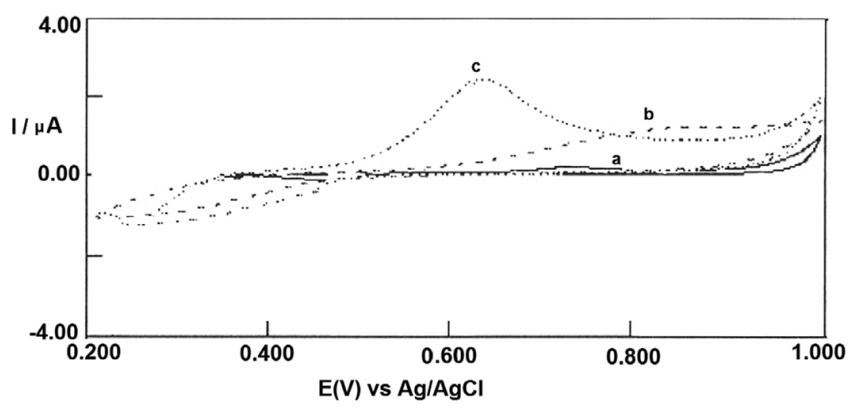

Figure 6. Cyclic voltammetric behavior of ethylene on (c) Ag/PANI/Pt, (b) PANI/Pt and (a) Pt in $0.25 \mathrm{~mol} \mathrm{~L}^{-1} \mathrm{Na}_{2} \mathrm{ClO}_{4}, \mathrm{v}=10 \mathrm{mV} \mathrm{s}^{-1}, \mathrm{~T}=20^{\circ} \mathrm{C}$

At PANI/Pt electrode the peak current $\left(\mathrm{I}_{\mathrm{pc}}\right)$ depends linearly on $v^{1 / 2}$ (Figure 7a), where $v$ is the scan rate, as expected for a diffusion-controlled reaction. In the Ag/PANI/Pt electrode case, the current peak depends linearly on $v$ (Figure $7 \mathrm{~b}$ ), as expected for an adsorption-controlled reaction.

Further evidence that the Ag micro-particles are mechanically stabilized in the polyaniline matrix was demonstrated by ultrasonication of the Ag/PANI/Pt electrodes.

The promoting effect of Ag particles in the polymeric matrix was observed only at loading level near $127 \mu \mathrm{A}$. At higher Ag, loading of $127 \mu \mathrm{C}$, the electrode showed no activity for ethylene oxidation; in this case, scanning electron microscopy shows that silver clusters were irregularly covering the polymer surface. This promoting effect has been explained based on a preferential ethylene adsorption on 

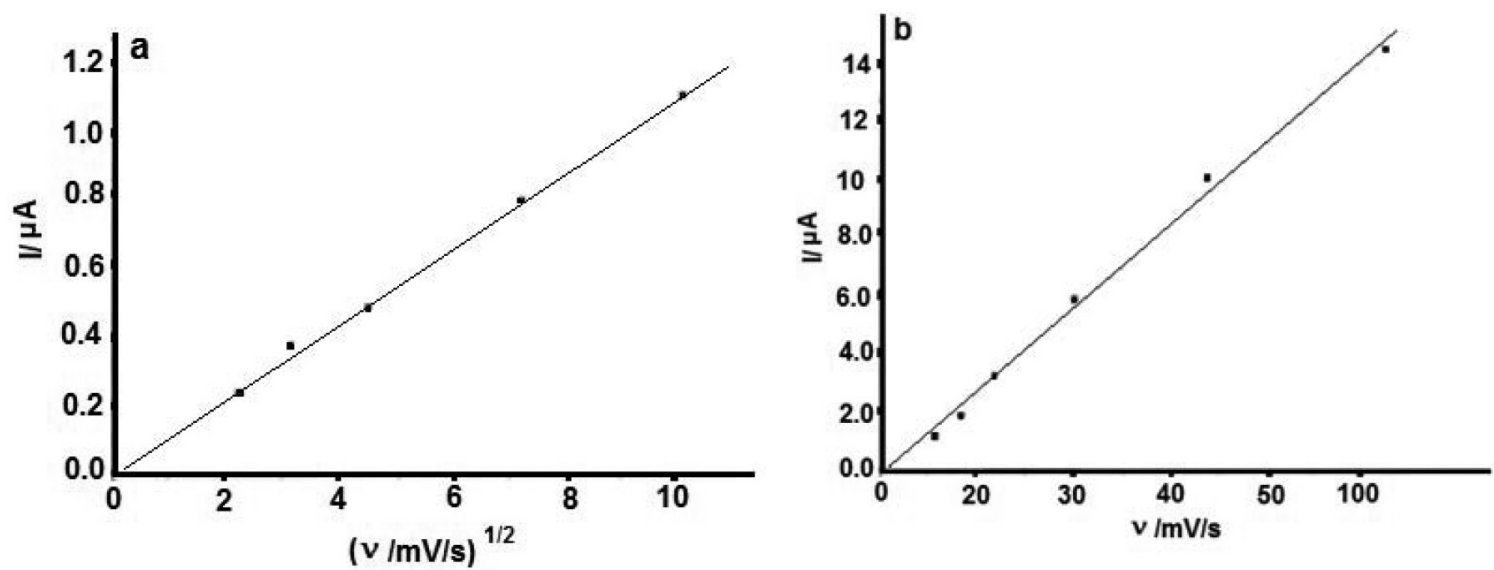

Figure 7. Effect of sweep speed in the ethylene oxidation at: (a) PANI/Pt and (b) Ag/PANI/Pt modified electrodes

Ag sites. A probable scheme with ethylene molecules adsorbing the $\mathrm{Ag}$ particle, which leads to the oxidation catalyses of the strongly adsorbed ethylene, is depicted in Figure 8. The ethylene is adsorbed preferentially on the Ag particles, probably oxidized to AgO.

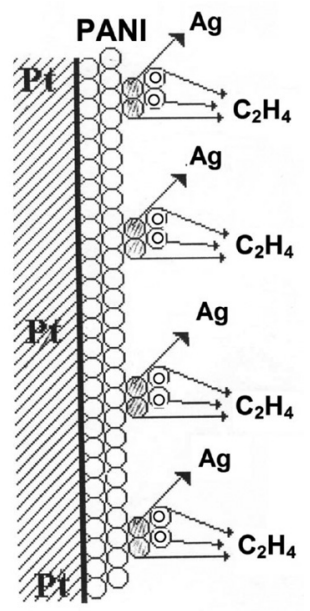

Figure 8. Model to explain the behavior of ethylene oxidation at the Ag/ PANI/Pt electrode

More studies, based on polymer film thickness, silver particle size variation (synthesizing silver nanoparticles) and the transient study, are clearly necessary to investigate this behavior, perform electrolysis of ethylene oxidation at modified electrodes and subsequent analysis of possible products by chromatography.

\section{CONCLUSION}

The Ag/PANI/Pt system showed ethylene oxidation activity greater by a factor of two compared to PANI/Pt. Ethylene oxidation currents were appreciable only at Ag loadings ca. $127 \mu \mathrm{c} \mathrm{cm}^{-2}$; at higher Ag, the system losses catalytic activity. These results indicate that, at low loading, the silver particle is deposited mainly inside the polymer on its internal surface and a minimum load is required for tridimensional dispersion. Cyclic voltammetric behavior of a polymer-catalyst assembly during the ethylene oxidation shows preferential adsorption for ethylene oxidation on the Ag/PANI/Pt electrode and a diffusion process for PANI/Pt.

\section{ACKNOWLEDGMENTS}

The authors would like to thank for the contribution of the
Technical University of Machala through the implementation of the System Reengineering Research, driven by its Academic Vice President, and Decanato de Investigación y Desarrollo Universidad Simón Bolívar (USB), Caracas-Venezuela, for financial support.

\section{REFERENCES}

1. Gileadi, E.; Stoner, G.; Bockris, J. M.; J. Electrochem. Soc. 1966, 113, 585 .

2. Wojtowicz, J.; Marincic, N.; Conway, B. E.; J. Chem. Phys. 1968, 48, 4333.

3. Green, M.; Weber, J.; Drazic, V.; J. Electrochem. Soc. 1964, 111, 721.

4. Dahmsand, H.; Bockris, J. O. M.; J. Electrochem. Soc. 1964, 111, 728.

5. Blake, A. R.; Sunderland, J. G.; J. Chem. Soc. A 1969, 6, 3015.

6. Harley, T. N.; Price, D.; J. Electrochem. Soc. 1970, 117, 448.

7. Vivekanandan, J.; Ponnusamy, V.; Mahudeswaran, A.; Vijayanand, P. S.; Arch. Appl. Sci. Res. 2011, 3, 147.

8. Reda, S. M.; Al-Ghannam, S. M.; Adv. Mater. Phys Chem. 2012, $2,75$.

9. Shama, I.; Lakshmi, G. B. V. S.; Siddiqui, A. M.; Husain, M.; Zulfequar, M.; Int. J. Polym. Sci. 2013, 2013.

10. Xia, Y.; Zhu, D.; Si, S.; Li, D.; Wu, S.; J. Power Sources. 2015, 283, 125

11. Ates, M.; Topkaya, E.; Prog. Org. Coat. 2015, 82, 33.

12. Shabani-Nooshabadi, M.; Karimian-Taheri, F.; RSC Adv. 2015, 5, 96601.

13. Lattach, Y.; Deronzier, A.; Moutet, J. C.; ACS Appl. Mater. Interfaces 2015, 7, 15866.

14. Hosseini, M.; Momeni, M. M.; J. Mater. Sci. 2010, 45, 3304.

15. Bhadra, S.; Singha, N. K.; Khastgir, D.; J. Appl. Polym. Sci. 2007, 104, 1904.

16. Borole, D. D.; Kapadi, U. R.; Kumbhar, P. P.; Hundiwale, D. G.; Mater. Lett. 2002, 56, 685.

17. Kinyanjui, J. M.; Wijeratne, N. R.; Hanks, J.; Hatchett, D. W.; Electrochim. Acta 2006, 51, 2825.

18. Tang, Z.; Liu, S.; Wang, Z.; Dong, S.; Wang, E.; Electrochem. Commun. 2000, 2, 32 .

19. Dui, L. J.; Mandi, Z.; Kova i ek, F.; J. Polym. Sci., Part A: Polym. Chem. 1994, 32, 105.

20. Kinyanjui, J. M.; Hanks, J.; Hatchett, D. W.; Smith, A.; Josowicz, M.; J. Electrochem. Soc. 2004, 151, D113.

21. Hand, R. L.; Nelson, R. F.; J. Am. Chem. Soc. 1974, 96, 3.

22. Wang, E.; Liu, A.; Anal. Chim. Acta 1991, 252, 53.

23. Glarum, S. H.; Marshall, J. H.; J. Phys. Chem. 1986, 90, 6076.

24. Nunziante, P.; Pistoia, G.; Electrochim. Acta 1989, 34, 223.

25. Wu, Q.; Xu, Y.; Yao, Z.; Liu, A.; Shi, G.; ACS Nano 2010, 4, 1963

26. Paul, E. W.; Ricco, A. J.; Wrighton, M. S.; J. Phys. Chem. 1985, 89, 1441. 